\title{
TO STUDY ANTIBIOTIC SUSCEPTIBILITY PATTERN OF STAPHYLOCOCCUS AUREUS ISOLATED FROM VARIOUS SKIN SAMPLES
}

\author{
NEHA*, BHARTI MITTU, ZARINA BEGUM, HARJOT PAL KAUR \\ Department of Life Science (Bio-Technology), I. K. Gujral Punjab Technical University, Jalandhar, Punjab, India. \\ Email: nehasharma0002@rediffmail.com
}

Received: 01 January 2019, Revised and Accepted: 20 May 2019

\section{ABSTRACT}

Objective: The study was carried out to check the antibiotic susceptibility profile of Staphylococcus aureus.

Methods: In this study for the isolation of strain, skin swabs from different parts of the body were taken aseptically with the set protocol. The sensitivity patterns of $S$. aureus were explored with different antibiotics for the treatment of $S$. aureus infections. We have studied the susceptibility pattern of various antibiotics including present all line therapies and other antibiotics using disk-diffusion method.

Results: It has been found that bacteria show the highest sensitivity toward third-line antibiotic tetracycline, trimethoprim, and minocycline. The different concentrations of these antibiotics were used to check the minimum inhibitory concentration and found to be effective even at the lower concentration of $0.01 \mathrm{mcg} /$ disc. Furthermore, the minimum inhibitory concentration of each antibiotic has been calculated to find the most effective antibiotic at low concentration. The isolates are found to be highly resistant toward ampicillin, ciprofloxacin, and cefotaxime.

Conclusion: The research concluded that the bacteria $S$. aureus are found to be more sensitive for chloramphenicol, kanamycin, and trimethoprim in first-line antibiotics, second-line antibiotics, and third-line antibiotics, respectively.

Keywords: Staphylococcus aureus, Antibiotic, Zone of inhibition, Minimum inhibitory concentration.

(C) 2019 The Authors. Published by Innovare Academic Sciences Pvt Ltd. This is an open access article under the CC BY license (http://creativecommons. org/licenses/by/4. 0/) DOI: http://dx.doi.org/10.22159/ajpcr.2019.v12i7.32868

\section{INTRODUCTION}

Staphylococcus is non-spore-forming cocci, a genus of Gram positive belongs to the Micrococcaceae family. These bacteria are generally present as normal human microbiota of the skin and nasal cavity. However, Staphylococcus aureus, Staphylococcus hominis, Staphylococcus haemolyticus, Staphylococcus epidermidis, and Staphylococcus saprophyticus are pathogenic in nature. S. aureus is proved to be the most pathogenic bacteria. It is able to coagulate plasma as it is coagulate positive in nature. It is commonly found in hospital and community-acquired nosocomial diseases. It is accountable as causative of a broad spectrum of skin diseases [1,2]. S. aureus has the ability to produce a wide range of toxins which include enterotoxins cause food poisoning, cytotoxins (general systemic toxins), and toxic shock superantigens [3] which leads to mild skin infection to serious life-threatening diseases [4]. In the 1880s, S. aureus was discovered causing skin and tissue infection and food poisoning. However, later, it becomes resistant to penicillin. Methicillin was used for the treatment of $S$. aureus infection. In 1961, S. aureus was given a name methicillinresistant $S$. aureus (MRSA) as it becomes resistant to beta-lactams including amoxicillin and methicillin. The major issue with the species of $S$. aureus is its resistance toward antibiotics [5]. The recognition of the antimicrobial resistance pattern is required for a researcher to widely spread a pragmatic and pathogen-specific therapy. The various classes of antimicrobial agents have become less effective due to the emergence of antimicrobial resistance often due to the selective pressure of antimicrobial usage [6]. This selective pressure is the result of extensive use of antibiotics and the overuse of existing drugs [7].

\section{METHODS}

\section{Collection of sample}

For the isolation of Staphylococcus, skin samples were collected in a sterile container using a sterile swab and transferred aseptically to the laboratory at $40^{\circ} \mathrm{C}$ for further testing.
Isolation of Staphylococcus

The isolation of bacteria was done using selective media, i.e., Mannitol salt agar. After the inoculation of the swab sample on the plate, it was incubated for $24 \mathrm{~h}$ at $37^{\circ} \mathrm{C}$. Presumptive $S$. aureus identified by the fermentation of mannitol as it produces yellow colonies. After the $24 \mathrm{~h}$ of incubation, the colonies obtained were further streaked to obtain the pure culture of bacteria [8].

\section{Identification}

The process of identification was done by morphological examination and biochemical tests. Gram staining was performed for the morphological identification. The various biochemical tests performed were citrate test, catalase test, oxidase test, Methyl Red - Voges Proskauer test, and sugar fermentation test [9-11].

\section{Antibiotic susceptibility test}

The commonly used antibiotics for the treatment of $S$. aureus associated diseases were tested for antibiotic susceptibility screening against these bacteria. The pure isolate was identified and selected for further study, by two methods: Spot-on-lawn and disk-diffusion method. Mueller-Hinton agar plates were prepared and $24 \mathrm{~h}$ old culture was inoculated. Antibiotic discs of different concentrations and various antibiotics were used and placed over the spread plates incubated at $37^{\circ} \mathrm{C}$ for $24 \mathrm{~h}$. An evaluation was done on the basis of the size of the zone of inhibition (ZOI) [12].

\section{RESULTS}

Out of 56 isolated samples, 9 strains were studied after isolating a pure colony on selective media. One strain was selected on the basis of biochemical characterization. Pure isolated bacteria showed yellowcolored colonies on Mannitol salt agar media (Fig. 1) which confirmed it as $S$. aureus and found to be Gram positive as showed purple-colored grapes like the cluster in round shape (Fig. 2) (Table 1). The biochemical tests were catalase positive, i.e., culture showed bubble formation after adding the hydrogen peroxide (Fig. 3), citrate positive (after $24 \mathrm{~h}$ 
incubation of inoculated Simmons' citrate agar color has changed from green to blue) (Fig. 4), oxidase positive, and methyl red positive tests (Table 2).

The antibiotic susceptibility of a selective isolate of $S$. aureus isolates revealed varying degrees of susceptibility patterns. Minimum inhibitory concentration has been calculated on the basis of ZOI for a different antibiotic with various ranges of concentrations. It has been found that the strain has shown maximum sensitivity toward tetracycline and chloramphenicol (Figs. 5-7). It was resistant toward nalidixic acid and ampicillin. The strain was also sensitive against ceftazidime, kanamycin, cefotaxime, and ciprofloxacin. A table has been formulated for different results which depict its sensitivity pattern (Tables 3-6).

The concentration used for all line therapy antibiotics and other antibiotics ranged from $0.01 \mathrm{mcg} / \mathrm{disc}$ to $240 \mathrm{mcg} / \mathrm{disc}$. The minimum effective concentration of ceftazidime was $4 \mathrm{mcg}$ and ZOI formed was $4 \mathrm{~mm}$. Ampicillin and cefotaxime showed its affectivity at minimum concentration $32 \mathrm{mcg}$ and ZOI formed was $5 \mathrm{~mm}$ and $7 \mathrm{~mm}$, respectively.

\section{DISCUSSION}

Omoigberale et al. investigated the antibiotic resistance pattern of S.aureus, isolated from vaginal and urethral swab specimens. The authors found that isolates were more sensitive for chloramphenical and tetracycline and resistant for nalidixic acid and ampicillin. These results are found to be similar to our study indicated [13]. In our study, it has been concluded that $S$. aureus is found to be more resistant toward

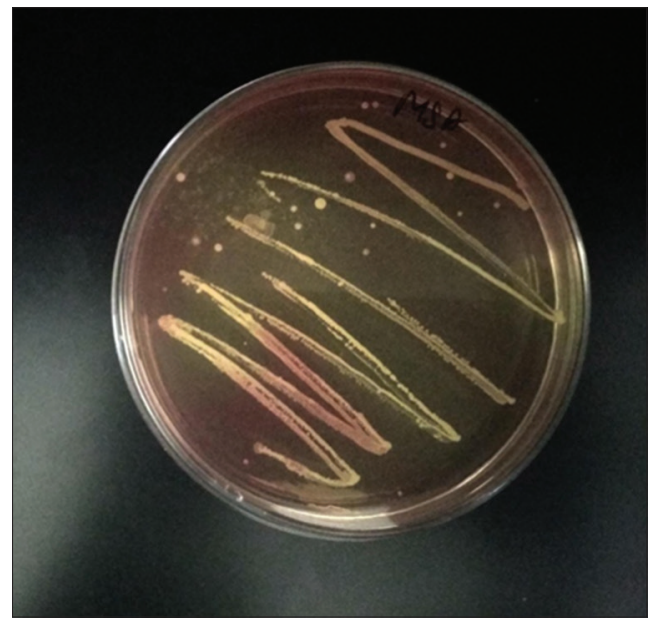

Fig. 1: Yellow-pigmented colonies on Mannitol salt agar

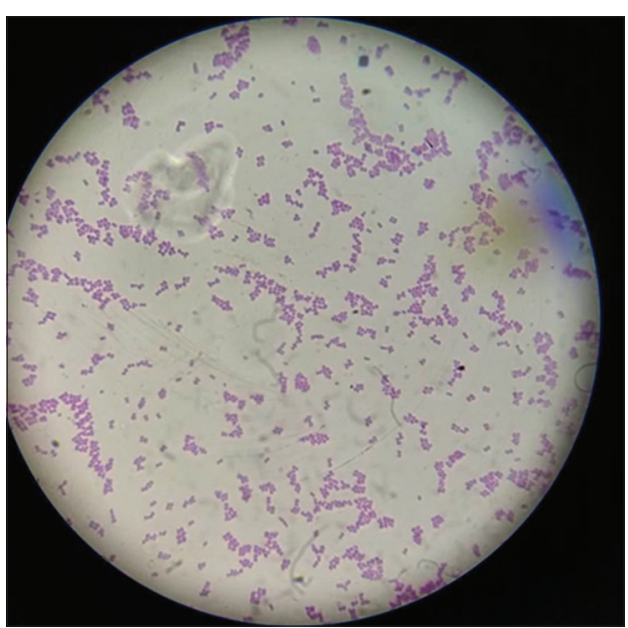

Fig. 2: Gram-positive, round shape cluster ampicillin and nalidixic acid and susceptible for chloramphenicol, cefotaxime, and tetracycline which is in contrast with the study of Salau et al. according to which antibiotic susceptibility pattern of $S$. aureus shows resistance to ampicillin (90.2\%), chloramphenicol (13.1\%), cefoxitin (32.8\%), and tetracycline (13.1\%) [14]. MRSA is found to be highly resistant to gentamicin (76\%), erythromycin $(67.03 \%)$, and ciprofloxacin (65.09\%) [15].

A recent study on resistance pattern of $S$. aureus performed was showed that $S$. aureus isolates were more sensitive to linezolid (96.8\%) than

Table 1: Morphological characterization of Staphylococcus aureus

\begin{tabular}{ll}
\hline Test & Observation \\
\hline Gram staining & Gram-positive (cocci) \\
\hline
\end{tabular}

Table 2: Biochemical characterization of Staphylococcus aureus

\begin{tabular}{lll}
\hline S. No. & Biochemical tests & Observation \\
\hline 1. & Catalase & Positive \\
2. & Oxidase & Negative \\
3. & Coagulase & Positive \\
4. & Mannitol fermentation & Positive \\
5. & Citrate & Positive \\
6. & Urease & Positive \\
\hline
\end{tabular}

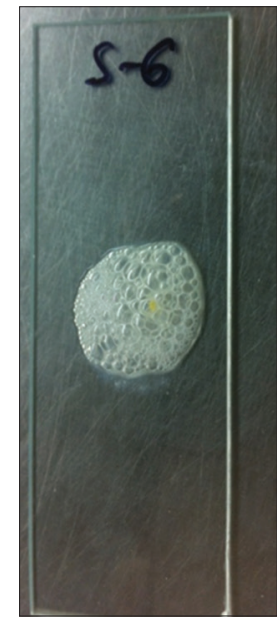

Fig. 3: Catalase test

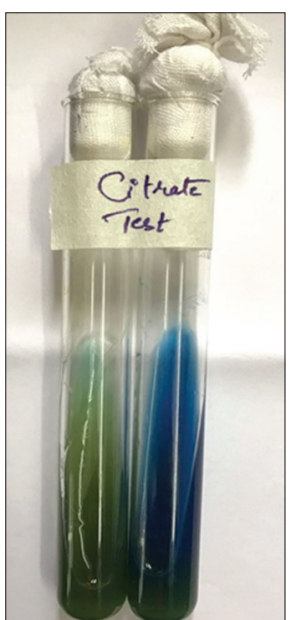

Fig. 4: Citrate test 
Table 3: Zone of inhibition showing effect of first-line antibiotics on Staphylococcus aureus

\begin{tabular}{llllllll}
\hline $\begin{array}{l}\text { Concentrations } \\
\text { (mg/disc) }\end{array}$ & \multicolumn{2}{l}{ First-line antibiotics } & & & & \multirow{2}{*}{ Mean \pm SD } \\
\cline { 2 - 6 } & Ampicillin & Cefotaxime & Chloramphenicol & Ceftazidime & Nalidixic acid & Sulfamethoxazole & \\
\hline 0.01 & $\mathrm{R}$ & $\mathrm{R}$ & 5 & $\mathrm{R}$ & $\mathrm{R}$ & 3 & $1.33 \pm 2.16$ \\
0.1 & $\mathrm{R}$ & $\mathrm{R}$ & 5 & 0.1 & $\mathrm{R}$ & 6 & $1.85 \pm 2.85$ \\
5 & $\mathrm{R}$ & $\mathrm{R}$ & 14 & 2.5 & 4 & 8 & $4.75 \pm 5.42$ \\
10 & $\mathrm{R}$ & $\mathrm{R}$ & 19 & 3.1 & 4 & 11 & $6.18 \pm 7.46$ \\
30 & 4.6 & 6.5 & 22 & 4.6 & 7 & 13 & $9.62 \pm 6.81$ \\
60 & 9.3 & 11.2 & 24 & 7.5 & 8 & 155 & $12.50 \pm 6.26$ \\
120 & 14 & 15 & 25 & 10 & 12 & 16 & $15.33 \pm 5.20$ \\
240 & 15.9 & 19.6 & 27 & 11.2 & 14 & 19 & $17.78 \pm 5.49$ \\
\hline
\end{tabular}

Table 4: Zone of inhibition showing effect of second-line antibiotics on Staphylococcus aureus

\begin{tabular}{lllll}
\hline Concentrations (mg/disc) & Second-line antibiotics & & \multirow{2}{*}{ Mean \pm SD } \\
\cline { 2 - 4 } & Ciprofloxacin & Kanamycin & Clindamycin & $0.00 \pm 0.00$ \\
\hline 0.01 & $\mathrm{R}$ & $\mathrm{R}$ & $\mathrm{R}$ & $0.00 \pm 0.00$ \\
0.1 & $\mathrm{R}$ & $\mathrm{R}$ & $\mathrm{R}$ & $2.00 \pm 2.00$ \\
5 & $\mathrm{R}$ & 2 & 4 & $3.67 \pm 3.51$ \\
10 & $\mathrm{R}$ & 4 & 10 & $6.00 \pm 5.29$ \\
30 & $\mathrm{R}$ & 8 & 11 & $8.33 \pm 7.37$ \\
60 & $\mathrm{R}$ & 17 & 13 & $13.33 \pm 3.51$ \\
120 & 10 & 17 & 13 & $15.67 \pm 2.31$ \\
240 & 17 & & & \\
\hline
\end{tabular}

Table 5: Zone of inhibition showing effect of third-line antibiotics on Staphylococcus aureus

\begin{tabular}{|c|c|c|c|c|c|}
\hline \multirow[t]{2}{*}{ Concentrations (mg/disc) } & \multicolumn{4}{|c|}{ Third-line antibiotics } & \multirow[t]{2}{*}{ Mean \pm SD } \\
\hline & Tetracycline & Trimethoprim & Linezolid & Minocycline & \\
\hline 0.01 & 5 & 5 & $\mathrm{R}$ & 3 & $3.25 \pm 2.36$ \\
\hline 5 & 8 & 8 & 7 & 6 & $7.25 \pm 0.96$ \\
\hline 10 & 9 & 12 & 10 & 8 & $9.75 \pm 1.71$ \\
\hline 30 & 10 & 14 & 11 & 11 & $11.50 \pm 1.73$ \\
\hline 60 & 12 & 15 & 12 & 13 & $13.00 \pm 1.41$ \\
\hline 120 & 15 & 15 & 12 & 17 & $14.75 \pm 2.06$ \\
\hline 240 & 19 & 18 & 15 & 21 & $18.25 \pm 2.50$ \\
\hline
\end{tabular}

Table 6: Minimum inhibitory concentration of antibiotics on Staphylococcus aureus

\begin{tabular}{ll}
\hline Antibiotics & MIC \\
\hline First-line antibiotics & \\
Ampicillin & 0.400313 \\
Cefotaxime & 0.388284 \\
Chloramphenicol & 0.065709 \\
Ceftazidime & 0.160025 \\
Nalidixic acid & 0.333678 \\
Sulfamethoxazole & 0.183194 \\
Second-line antibiotics & \\
Ciprofloxacin & 0.45914 \\
Kanamycin & 0.304479 \\
Clindamycin & 0.321107 \\
Third-line antibiotics & \\
Tetracycline & 0.215788 \\
Trimethoprim & 0.136798 \\
Linezolid & 0.157019 \\
Minocycline & 0.246289 \\
\hline
\end{tabular}

MIC: Minimum inhibitory concentration

tetracycline (90.9\%) and piperacillin/tazobactam (80.6\%). These results are also similar to our study [16].
In the previous study, ampicillin recorded the highest rate of resistance of $90.2 \%$ with a sensitivity of $9.8 \%$. The ability of $S$. aureus to resist this antibiotic is due to the ability of $S$. aureus to produce a plasmidencoded beta-lactamase that hydrolyzes the beta-lactam ring of this class of antibiotic which is essential for its antimicrobial activities [17], and also, the high resistance to ampicillin could be due to the misuses or abuse of antibiotics which is common phenomenon in developing countries $[18,19]$

The intermediate resistance for cefotaxime has been founded by a previous study. This agrees with the result of the present study which shows resistance of $S$. aureus toward cefotaxime at concentration 16 mcg produced ZOI $32 \mathrm{~mm} \mathrm{[20].}$

S. aureus has been found to be more sensitive for chloramphenicol and it has been reported for the use of chloramphenicol antibiotic in case of multidrug-resistant Gram-positive bacteria [21]. This interpretation is exact as our study has proved the effectiveness of chloramphenicol even at minimum concentration $[22,23]$.

Statistical analysis

For the statistical analysis, one-way ANOVA used to determine the significance of the results obtained. Level of significance was adjusted at 0.05 and results were said to be significant if their 


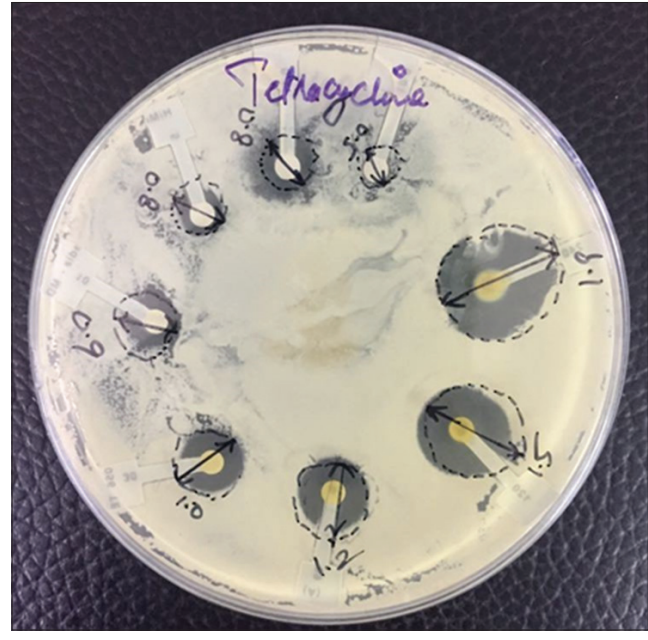

Fig. 5: Zone of inhibition ( $\mathrm{mm}$ ) tetracycline

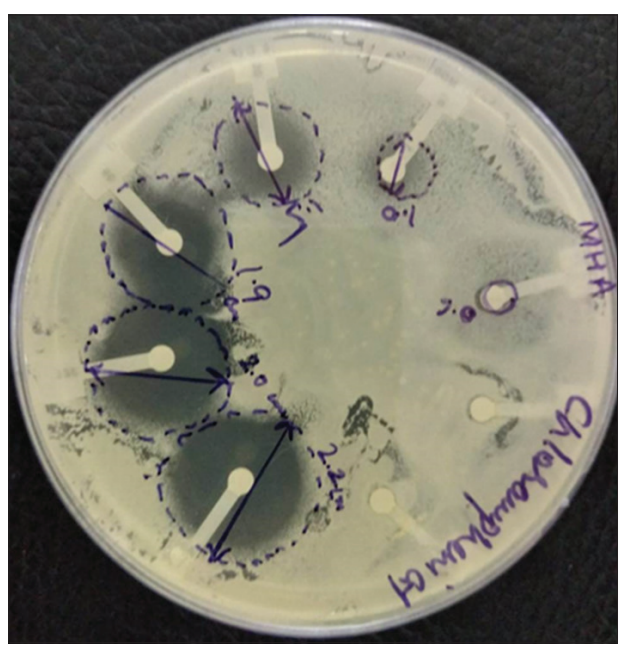

Fig. 6: Effect of chloramphenicol

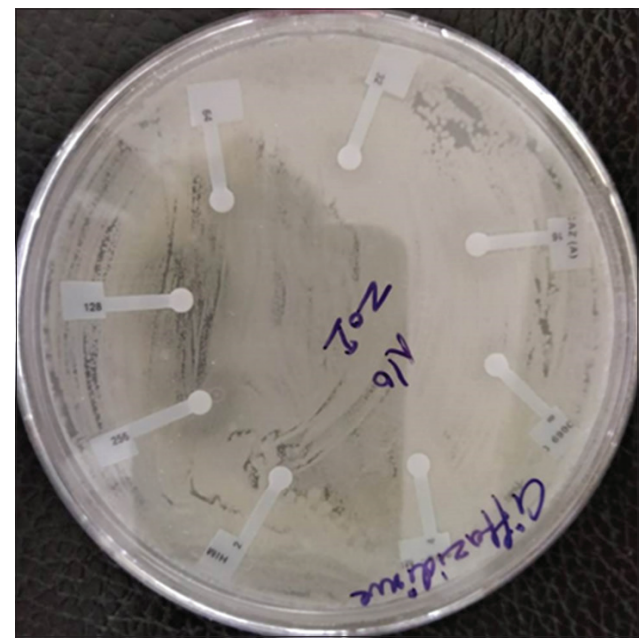

Fig. 7: No zone of inhibition

$\mathrm{p}<0.05$ and $\mathrm{F}_{\text {crit }}<\mathrm{F}$-value according to one-way ANOVA. Minimum inhibitory concentrations of all the antibiotics calculated show that chloramphenicol, kanamycin, and trimethoprim are more effective in first-line antibiotics (Fig. 8), second-line antibiotics, and third-line antibiotics, respectively (Graphs 1-3).

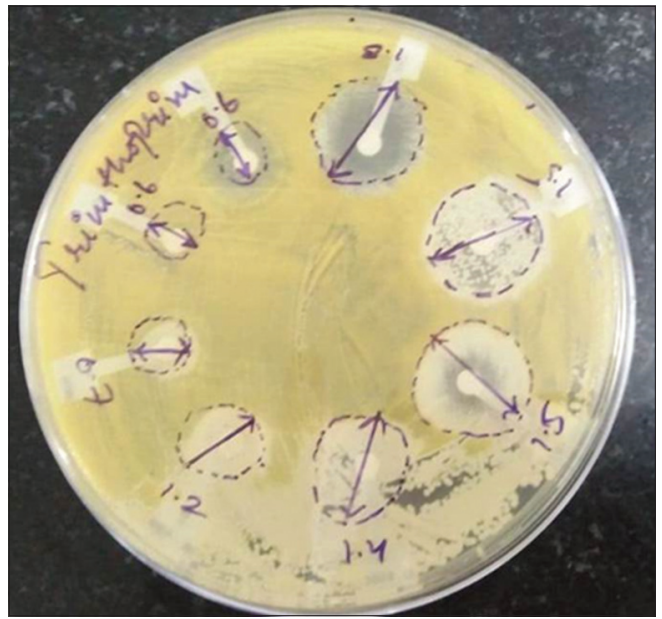

Fig. 8: Effect of trimethoprim

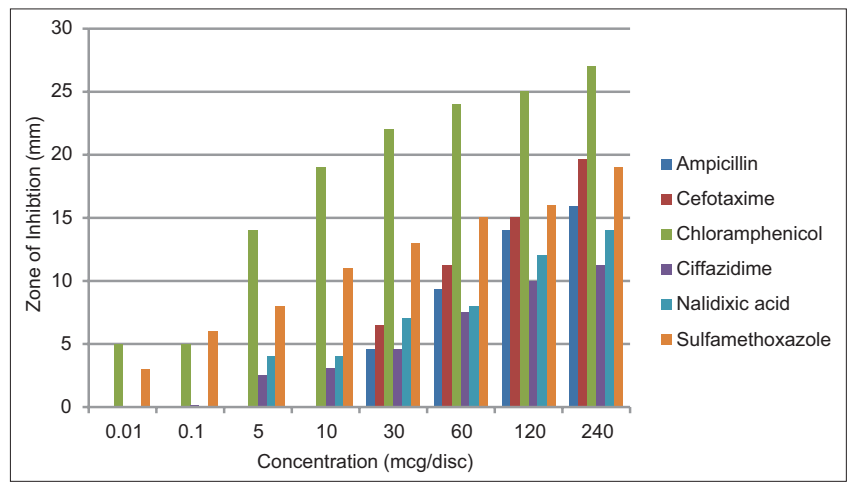

Graph 1: Zone of inhibition of first-line antibiotics as various concentrations

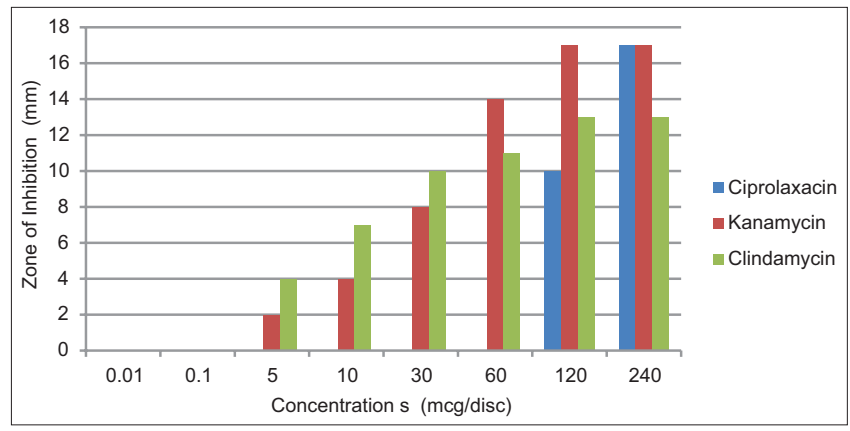

Graph 2: Zone of inhibition of second-line antibiotics as various concentrations

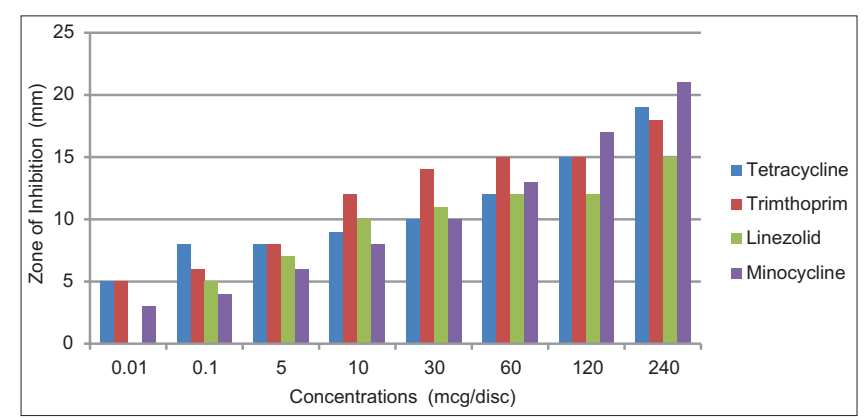

Graph 3: Zone of inhibition of third-line antibiotics as various concentrations 


\section{CONCLUSION}

In the present investigation, it was found that $S$. aureus shows sensitivity toward first-, second-, third-line and other antibiotic. The bacteria found to be more sensitive toward third-line antibiotics, and minimum inhibitory concentration of antibiotics found to be is $0.01 \mathrm{mcg} / \mathrm{disc}$.

\section{ACKNOWLEDGMENT}

The author wants to show gratitude to Mr. Nitin Sharma of orbit biotech for his ideas and suggestions at each step of my work. Moreover, author wants to special thank IK Gujral Punjab Technical University, Jalandhar, for providing me opportunity of doing the research work.

\section{AUTHORS' CONTRIBUTIONS}

Mittu B and Neha conceived and designed the experiments. Neha collected samples and performed laboratory analysis. Begum $\mathrm{Z}$ and Kaur $\mathrm{H}$ guide to wrote the manuscript and finalize the data. All authors have read and approved the final draft of the manuscript.

\section{CONFLICTS OF INTEREST STATEMENT}

The author(s) declared no potential conflicts of interest with respect to research, authorship, and/or publication of this article.

\section{REFERENCES}

1. Samson OO, Anthony OE. Prevalence of multi-drug resistant Staphylococcus aureus in clinical specimens obtained from patients attending the university of Benin teaching hospital, Benin City, Nigeria. J Natural Sci 2013;3 Suppl 5:154-9.

2. Rahimi F, Bouzari M, Katouli M, Pourshafie MR. Antibiotic resistance pattern of methicillin resistant and methicillin sensitive Staphylococcus aureus in Tehran. Iran. Jundishapur J Microbiol 2013;6 Suppl 2:144-9.

3. Reynolds FJ. Biology 2420 Lab Manual. Richland College, New York: Fall Publishers; 2011.

4. Onile BA, Odugbemi TO, Nwofor C. Antibiotic susceptibility of bacterial agents of Septicemia in Ilorin. Niger Med Pract 1985;9 Suppl 4:16-8.

5. Meyers HF, Ernest J, Allan G. A review of Medical Pharmacology. Vol. 49. Los Altos: Lange Medical Publishers; 1970. p. 467-74.

6. Oskay M, Oskay D, Kalyoneu F. Activity of some plant extracts against multidrug resistant human pathogens. Iran J Pharm Res 2009;8 Suppl 4:293-300

7. McGowan JE. Resistance in non-fermenting gram-negative bacteria: Multidrug resistance to the maximum. Am J Infect Control 2006;34:29-37.

8. Thornsberry C, McDougal LK. Successful use of broth microdilutio in susceptibility tests for methicillin-resistant (heteroresistant) staphylococci. J Clin Microbiol 1983;18:1084-91.
9. Bergey DH, Krieg NR, Holt JG. Bergey's Manual of Systematic Bacteriology. Baltimore, MD: Williams and Wilkins; 1984.

10. Akpaka PE, Monecke S, Swanston WH, Rao AC, Schulz R, Levett PN. Methicillin sensitive Staphylococcus aureus producing panton-valentine leukocidin toxin in Trinidad and Tobago: A case report. J Med Case Rep 2011;5:157.

11. Kaur B, Balgir P, Mittu B, Chauhan A. Purification and physicochemical characterization of anti Gardnerella vaginalis bacteriocin HV6b produced by Lactobacillus fermentum isolate from human vaginal ecosystem bacteriocin HV6b produced by Lactobacillus fermentum isolate from human vaginal ecosystem. Am J Biochem Mol Biol 2013;3 Suppl 1:91-100

12. Oyeleke SB, Manga BS. Essentials of Laboratory Practicals in Microbiology. $1^{\text {st }}$ ed. Minna, Nigeria: Tobest Publishers; 2008. p. 63-5.

13. Omoigberale MN, Iyamu MI, Amengialue OO, Egharevba AP, Edobor O. Antibiotic resistance pattern of Staphylococcus aureus isolated from high vaginal swab and urethral swab specimens. Am J Res Commun 2014;2:96-107.

14. Salau OA, Yakubu SE, Ado SA. Prevalence and antibiotic susceptibility pattern of Staphylococcus aureus from patients attending some selected hospitals in Samaru, Zaria, Nigeria. Int J Health Sci Res 2015;5:79-84.

15. Bhooshan S, Prasad J, Dutta A, Vandana KE, Mukhopadhyay C. Reduced susceptibility of MRSA to vancomycin. Int J Pharm Pharm Sci 2016;8:321-2.

16. Basavaraj CM, Peerapur B, Jyothi P. Drug resistance patterns of clinical isolates of Staphylococcus aureus in tertiary care center of South India. Int J Pharm Pharm Sci 2015;7:70-2.

17. Oncel T, Ica T, Akpan M. Beta-lactamase production rate and antimicrobial susceptibility of Staphylococcus aureus isolated from clinical and subclinical mastitis case in Turkey. J Vet Med 2004;155 Suppl 7:385-8.

18. Aligholi M, Emaneini M, Jabalameli F, Shahsavan S, Dabiri H, Sedaght $\mathrm{H}$, et al. Emergence of high-level vancomycin-resistant Staphylococcus aureus in the imam Khomeini hospital in Tehran. Med Princ Pract 2008; 17:432-4.

19. Olasupo NA, Fitzgerald DJ, Gasson MJ, Narbad A. Activity of natural antimicrobial compounds against Escherichia coli and Salmonella enterica serovar typhimurium. Lett Appl Microbiol 2003;37:448-51

20. Madhusudhan NS, Deepa S, Shoba DN. Correlation of cefoxitin disc diffusion test and oxacillin disc diffusion test for detecting mecA mediated oxacillin resistant Staphylococcus aureus. J Pharm Biomed Sci 2011;10 Suppl 2:2230-7885.

21. Anderson ME, Lefebvre SL, Weese JS. Evaluation of prevalence and risk factors for methicillin-resistant Staphylococcus aureus colonization in veterinary personnel attending an international equine veterinary conference. Vet Microbiol 2008;129:410-7.

22. Kaur H, Dhir K, Kaur J, Mittu B, Chauhan A. Synthesis and evaluation of diorganotin $(1 \mathrm{~V})$ and triorganotin $(1 \mathrm{~V})$ derivatives of aspirin, paracetamol and metronidazole as antimicrobial agents. Am J Drug Discov Dev 2013;3 Suppl 1:13-22.

23. Lentino JR, Narita M, Yu VL. New antimicrobial agents as therapy for resistant gram-positive cocci. Eur J Clin Microbiol Infect Dis 2008;27:3-15 